\title{
Positive Expectations in the Early Years of Marriage: Should Couples Expect the Best or Brace for the Worst?
}

\author{
James K. McNulty \\ The Ohio State University
}

\author{
Benjamin R. Karney \\ University of Florida
}

\begin{abstract}
The current study examined whether the effects of positive expectations on changes in marital satisfaction over the first 4 years of marriage were moderated by the nature of spouses' interaction behaviors and relationship attributions. Consistent with predictions, when spouses' skills were most positive, positive expectations predicted more stable satisfaction over time whereas less positive expectations predicted steeper declines. Alternatively, when spouses' skills were most negative, positive expectations predicted steeper declines in satisfaction over time whereas less positive expectations predicted more stable satisfaction. Thus, in contrast to the idea that expectations in the early years of marriage exert main effects on satisfaction, the current findings suggest that the effects of expectations interact with the skills partners bring to their relationships.
\end{abstract}

Things become better when you expect the best instead of the worst.

—Norman Vincent Peale, The Power of Positive Thinking (1952)

Blessed is he who expects nothing, for he shall never be disappointed.

-Alexander Pope, Letter to Gay (1727; as cited in Bartlett \& Dole, 1919/2000)

Although they lived centuries apart, poet Alexander Pope (see Bartlett \& Dole, 1919/2000) and motivational writer Norman Vincent Peale (1952) agreed that what people expect to receive affects how they evaluate what they actually receive. The authors differ, however, in how they described the nature of this effect. According to Peale, expectations inspire outcomes that are consistent with those expectations. Thus, he argued that positive expectations should be cultivated because they direct people toward positive outcomes. According to Pope, however, any expectations

James K. McNulty, Department of Psychology, The Ohio State University; Benjamin R. Karney, Department of Psychology, University of Florida.

Portions of this article were presented to the Graduate School at the University of Florida as James K. McNulty's doctoral dissertation. Preparation of this article was supported by National Institute of Mental Health Grant MH59712 and by a Research Development Award from the College of Liberal Arts and Sciences at the University of Florida to Benjamin R. Karney.

We thank Chris Adams, Jessica Baker, Krista Bernard, Mark DaSilva, Nancy Frye, Katherine Leong, Sacha Lindekens, Giovanni Montrone, Kimberly Mosler, Lisa Neff, Rachel Nitzburg, Joanna Sadowski, Jennifer Smith, Kara Sweeney, and Mark Trujillo for their assistance in data collection, observational coding, and data entry. Additionally, we thank the members of James K. McNulty's dissertation committee, James Algina, Barry Schlenker, Larry Severy, and James Shepperd, for their insightful comments concerning this research.

Correspondence concerning this article should be addressed to James K. McNulty, Department of Psychology, The Ohio State University, 1680 University Drive, Mansfield, OH 44906. E-mail: menulty.36@osu.edu leave people vulnerable to disappointment should they fail to be met. Thus, he argued that positive expectations should be avoided because they increase the likelihood of experiencing disappointments.

The difference between these two views mirrors an ongoing debate within research on intimate relationships. Although studies agree that what partners expect to receive in their relationships affects their evaluations of those relationships (e.g., Baucom, Epstein, Rankin, \& Burnett, 1996; Downey, Freitas, Michaelis, \& Khouri, 1998; Fletcher, Simpson, \& Thomas, 2000; Knee, 1998; McNulty \& Karney, 2002, Murray, Holmes, \& Griffin, 1996b; Stanley, Blumberg, \& Markman, 1999), there is little consensus about the direction of this effect. One line of research suggests that positive expectations lead to positive outcomes. On the basis of this idea, some authors have argued that positive expectations about a relationship are necessary for developing and maintaining healthy relationship functioning. For example, in one approach to preventing marital distress, researchers argued that "holding extreme standards that ask a great deal of the marriage is positively related to marital adjustment" (Baucom et al., 1996, p. 83). In contrast, another line of research suggests that positive expectations lead to disappointment. On the basis of this idea, some authors have argued that positive expectations can be a source of marital dysfunction. For example, in an alternative approach to preventing marital distress, researchers argued that "couples are at increased risk when expectations are unreasonable" (Stanley et al., 1999, p. 285).

Do positive expectations help maintain satisfaction, or are they likely to lead to declines in satisfaction? The goal of the current study is to address this question through longitudinal data on expectations and the development of marital satisfaction in newlywed couples. To this end, the remainder of this introduction is organized into three sections. The first section examines research on the different functions of expectations, showing that positive expectations may lead to positive outcomes when confirmed through processes of expectancy confirmation but may lead to 
negative outcomes when they serve as counterfactuals. The second section identifies qualities of relationships that should moderate the likelihood of expectancy confirmation and therefore predict when positive expectations will lead to positive versus negative outcomes. The final section describes a study designed to examine whether two qualities, the nature of couples' interaction behaviors and the nature of their relationship attributions, moderate the effects of positive expectations on changes in satisfaction over the first years of marriage.

\section{Positive Expectations and Relationship Functioning}

Expectations about the future of an intimate relationship may serve two different functions in evaluations of that relationship. First, expectations can serve as goal structures that motivate processes of expectancy confirmation (for a review, see Snyder, 1984). Given a goal expressed by an expectation for the relationship, confirmation of that expectation can occur through two mechanisms. Perceptual confirmation occurs when prior expectations for an event lead people to interpret the details of the event in ways that give rise to expectancy-consistent evaluations of the event (Darley \& Gross, 1983; Hastorf \& Cantril, 1954; Kelley, 1950; Miller \& Turnbull, 1986). Behavioral confirmation occurs when prior expectations for an event give rise to expectancyconsistent behaviors during the event (Darley \& Fazio, 1980; Jussim, 1986; Merton, 1948; Rosenthal \& Jacobson, 1968; Snyder, Tanke, \& Berscheid, 1977).

A number of studies have suggested that both processes operate in close relationships (e.g., Downey et al., 1998; Fletcher et al., 2000; Knee, 1998; McNulty \& Karney, 2002; Murray et al., 1996b). For example, in research demonstrating behavioral confirmation, women expecting to be rejected by their partners tended to engage in behaviors that predicted greater negative feelings in their partners following the interaction (Downey et al., 1998). In research providing evidence for perceptual confirmation, spouses' general expectations about an upcoming problem-solving discussion were positively associated with their subsequent appraisals of the interaction, independent of the behaviors they exchanged during the discussion (McNulty \& Karney, 2002). In other words, partners perceived the interaction in a manner consistent with their prior expectations, regardless of the behaviors that were exchanged.

That both processes may operate in close relationships suggests that to the extent that they are likely to be confirmed, positive expectations should be beneficial to relationships. Research on related constructs appears consistent with this idea (Fletcher et al., 2000; Murray et al., 1996b). For example, Fletcher et al. (2000), in research on relationship standards, reported that romantic partners were more satisfied with their relationships when they possessed higher ideal standards for their relationships. Higher standards, like positive expectations, may encourage consistent perceptions or inspire consistent behaviors leading to increased relationship satisfaction.

In contrast to serving as goal structures, a second function of expectations is that they can serve as counterfactuals to which people compare their actual outcomes. Decision affect theory (DAT; Mellers, Schwartz, Ho, \& Ritov, 1997) suggests that how people feel about their outcomes is determined in part by counterfactual thinking - comparing what occurred with what might have occurred. According to DAT, a negative outcome feels less disappointing when compared with an alternative, worse outcome, and a positive outcome feels less satisfying when compared with an alternative, better outcome. Accordingly, people should be happy when their outcomes exceed their expectations but disappointed when their outcomes fall short of their expectations. Research outside close relationships supports DAT (Medvec, Madey, \& Gilovich, 1995; Mellers et al., 1997; Shepperd \& McNulty, 2002). Shepperd and McNulty (2002), for example, led participants to expect that they were either likely or unlikely to test positive for a threatening (but fictitious) medical condition. All participants then tested themselves for the medical condition and subsequently received feedback that they had tested positively or negatively for the disease. Of the participants who learned they had tested positive, those who held the most optimistic expectations (e.g., those who expected not to have the disease) felt most discouraged after learning the test results. Similarly, of the participants who learned they had tested negative, those whose expectations were optimistic felt least relieved after learning the test results. In other words, following both positive and negative outcomes, people who expected the best felt the worst.

Do partners who hold high expectations for their relationships similarly risk being disappointed? Theoretical work within the literature on close relationships suggests that they do. According to interdependence theory (Thibaut \& Kelley, 1959), partners determine their satisfaction with the relationship by comparing the outcomes they receive in their relationships with the standards they have for those relationships. In line with DAT, if partners' outcomes exceed their standards, they will be satisfied with their relationships. In contrast, if partners' outcomes do not meet their standards, they will be disappointed and therefore less satisfied with their relationships.

Empirical evidence within the literature on close relationships is consistent with these predictions. For instance, in the previously discussed Fletcher et al. (2000) study, the positive association between ideal standards and relationship outcomes was qualified by partners' perceptions of whether their standards were being met. Partners who perceived that their ideal standards were not being met tended to be least happy in their relationships. In related work, Eidelson and Epstein (1982) developed an inventory to measure beliefs about relationships they thought would be unrealistic for most people: the belief that disagreement is always destructive, the belief that partners should read each other's minds, the belief that partners cannot change, the belief in sexual perfectionism, and the belief that the sexes are inherently different. Cross-sectionally, endorsement of these beliefs has been associated with lower levels of satisfaction with the relationship (see also Epstein \& Eidelson, 1981; Jones \& Stanton, 1988). One explanation for such associations is that spouses who expect their own relationships to meet these standards may be especially disappointed when their relationships inevitably fail to measure up.

So when is it beneficial to start a relationship with positive expectations? The effects of expectations appear to depend on whether those expectations function as goal structures, likely to encourage expectancy confirmation, or as counterfactuals, with which partners compare their actual outcomes. When they inspire perceptual and behavioral confirmation, positive expectations appear to benefit relationships. When expectancy confirmations fail, however, positive expectations may serve as contrasts to actual 
outcomes, leading partners to evaluate their actual outcomes more negatively.

\section{Conditions of Expectancy Confirmation}

To the extent that expectancy confirmation moderates the impact of positive expectations on relationship outcomes, understanding the role of expectations in relationships requires understanding when positive expectations are more or less likely to be confirmed. Within the context of relationship outcomes, confirmation is not likely to be categorical. Rather, partners may possess latitudes of confirmation or disconfirmation, similar to Sherif's (1960) concept of latitudes of acceptance and rejection of attitudes. Just as Sherif described perceivers encountering a wide range of persuasive communications, romantic partners are likely to encounter a wide range of experiences as their relationships develop. Experiences that fall within a partner's latitude of confirmation will be seen as confirming initially positive expectations. Experiences that fall outside latitudes of confirmation will be seen as disconfirming initially positive expectations.

The likelihood that partners will perceive their expectations as having been confirmed may therefore depend on their ability to create events and, failing that, interpret events that fall within the latitude of acceptance of those expectations (Miller \& Turnbull, 1986; for other factors that may moderate the expectancyconfirmation effect, see also Swann, 1984). For example, Jussim (1986) pointed out that behavioral confirmation is generally more likely to occur to the extent that people are capable of behaving in ways that confirm their expectations. Within intimate relationships, partners who are more skillful communicators and problem solvers should be better able to arrange experiences that confirm initially positive expectations. Indeed, longitudinal research demonstrates that the spouses who are more skilled at resolving conflicts and behaving constructively tend to be more satisfied with their relationships over time (e.g., Gottman, 1994; Gottman, Coan, Carrere, \& Swanson, 1998; Huston, Caughlin, Houts, Smith, \& George, 2001; Karney \& Bradbury, 1997). Accordingly, behavioral skills in the early years of the relationship may moderate the effects of positive expectations on relationship outcomes by creating experiences that confirm or disconfirm those expectations. That is, for partners who tend be skillful communicators, positive expectations may be beneficial, directing partners to exploit their skills to the benefit of the relationship, and less positive expectations may be detrimental by preventing partners from taking advantage of their skills. For partners who tend to be less skillful, however, positive expectations may be detrimental because the lack of behavioral skills may lead these couples to encounter experiences that disconfirm those expectations, resulting in disappointment. Such partners may benefit from less positive expectations instead because such expectations will serve as less severe contrasts to their potentially more negative experiences.

If behavioral confirmation fails, partners may still confirm positive expectations if they are able and willing to engage in perceptual confirmation, interpreting events in a manner consistent with their expectations (Miller \& Turnbull, 1986). The robust literature on attributions has revealed how the tendency to interpret specific relationship events positively predicts greater long-term satisfaction with relationships (Bradbury \& Fincham, 1990). Even controlling for the covariance between attributions and relationship satisfaction over time, the initial attributional tendencies of newlyweds have been shown to predict trajectories of satisfaction and divorce over the first years of marriage (Karney \& Bradbury, 2000). In line with this research, partners who demonstrate the ability to interpret ambiguous events positively early in the relationship may be more able to perceive experiences as falling within the latitude of confirmation of their initially positive expectations throughout the relationship. Accordingly, the tendency to make positive versus negative attributions for the events that occur in the relationship may be a second factor that moderates the effects of positive expectations on relationship outcomes. For partners who tend to make charitable attributions for their partners' negative behaviors, positive expectations may be beneficial, inspiring them to take advantage of the cognitive relationship maintenance strategies they possess, and less positive expectations may be detrimental by inhibiting them from seeing things in a positive light. For partners less able to forgive their partners, however, positive expectations may be detrimental, raising a standard that the relationship can never achieve. These partners too may benefit from less positive expectations, because such expectations will serve as less severe contrasts to the partners' potentially more negative experiences.

\section{Overview of the Current Study}

To contribute to the ongoing debate about the effects of positive expectations on relationships, we examined whether the longitudinal effects of positive expectations on the trajectory of marital satisfaction were moderated by the quality of spouses' marital interactions and attributions. First-married couples participating in a broader study of relationship development were asked to report their expectations for various relationship outcomes shortly after their wedding. Newlyweds were an especially appropriate sample for the current study for two reasons. First, as Jussim and Eccles (1995) pointed out, over the course of an ongoing relationship, specific expectations are likely to become accurate reflections of past experience. In the current sample of newlyweds, specific expectations and prior experience were less likely to be confounded, leaving open the possibility that initially positive expectations may still be confirmed or disconfirmed. Second, couples in the very early stages of their relationships are frequently the targets of interventions aimed directly at modifying expectations (e.g., Stanley et al., 1999). Before such interventions become accepted in premarital and early-marital therapy programs, it seems relevant to examine the effects of expectations in a recently married sample.

In addition to expectations, spouses reported their satisfaction with the relationship, responded to a measure of relationship attributions, and engaged in two videotaped problem-solving discussions. Subsequent to that initial assessment, these couples provided reports of their relationship satisfaction every 6 months for 4 years, for a total of eight waves of marital satisfaction data.

To the extent that spouses behave more positively during their interactions with each other or tend to make more positive attributions for their partners' behaviors, we predicted that positive expectations should function as goal structures likely to be confirmed by processes of expectancy confirmation. Under these circumstances, positive expectations should be associated with more stable relationship satisfaction over time because spouses' skills should allow them to confirm their positive expectations, but 
less positive expectations should be associated with steeper declines in satisfaction over time because they indicate a failure or an unwillingness to take advantage of opportunities for expectancy confirmation. In contrast, to the extent that spouses behave more negatively during their interactions with each other or tend to make more negative attributions for their partners' behaviors, their positive expectations should function as counterfactuals because such partners should lack the skills to confirm those expectations. Under these conditions, positive expectations should lead to steeper declines in satisfaction because they provide the most striking contrasts to actual outcomes. Less positive expectations, alternatively, should be associated with more stable relationship satisfaction over time because they provide less striking contrasts to actual outcomes.

\section{Method}

\section{Participants}

All of the couples participating in this research were newlyweds, assessed within the first 6 months of both partners' first marriage. Couples were solicited from the community using two methods. The first method was to place advertisements in community newspapers and bridal shops, offering up to $\$ 300$ to couples willing to participate in a study of newlyweds. The second method was to review the applications of couples who had applied for marriage licenses in Alachua County, Florida. In Alachua County, marriage licenses are available to the public and contain data on spouses' ages, whether or not this is their first marriage, and the date of the wedding. Couples who were eligible for the study based on these criteria were sent letters offering them up to $\$ 300$ to participate in a study of newlyweds. Couples responding to either method of solicitation were screened in a telephone interview to determine whether they met the following criteria: (a) This was the first marriage for each partner; (b) the couple had been married less than 3 months; (c) neither partner had children; (d) each partner was at least 18 years of age, and wives were less than 35 years of age (to allow that all couples were capable of conceiving children over the course of the study); (e) each partner spoke English and had completed at least 10 years of education (to ensure comprehension of the questionnaires); and (f) the couple had no immediate plans to move away from the area. Nearly 300 couples responded to these solicitations; the 82 eligible couples who arrived for their scheduled interview made up the current sample. Analyses revealed no significant differences in age or years of education between couples recruited through the different types of solicitations (D'Angelo \& Karney, 1999).

Husbands were an average of 25.1 years old $(S D=3.3)$ and had received 16.3 years of education $(S D=2.4)$. Forty percent were employed full time, and $54 \%$ were full-time students. Wives were an average of 23.7 years old $(S D=2.8)$ and had received 16.3 years of education $(S D=1.2)$. Thirty-nine percent were employed full time, and $50 \%$ were full-time students. Slightly over $70 \%$ of the sample was Christian (over $45 \%$ was Protestant), and $83 \%$ of husbands and $89 \%$ of wives were White. The average combined income of couples was less than $\$ 20,000$ per year. ${ }^{1}$

\section{Procedure}

Couples meeting eligibility requirements were scheduled to attend a 3-hr laboratory session. Before the session, they were mailed a packet of questionnaires to complete at home and bring with them to their appointment. This packet included self-report measures of marital satisfaction, relationship attributions, measures of expectations for the relationship and the partner, as well as a letter instructing couples to complete all questionnaires independently of one another. As part of a subsequent laboratory session, spouses each identified an area of difficulty in the marriage and then participated in two 10-min videotaped discussions within which they were left alone to "work towards some resolution or agreement" for each area of difficulty. The order of the two interactions was determined through a coin flip. After completing their interactions, couples were paid $\$ 50$ for participating in this phase of the study.

At approximately 6-month intervals subsequent to the initial assessment, couples were recontacted by phone and then mailed additional marital satisfaction questionnaires along with postage-paid return envelopes and a letter of instruction reminding couples to complete forms independently of one another. This procedure was used at every 6-month interval except for Time 5, during which couples returned to the laboratory again. Couples were paid $\$ 25$ to continue participating at each follow-up through the mail and $\$ 50$ for the lab session at Time 5. This study examined eight waves of marital satisfaction data, covering approximately the first 4 years of marriage. Thus, analyses are based on data obtained from marital satisfaction measures assessed at Times 1-8 and behavioral and attribution measures assessed at Time 1. Behavioral and attribution measures at Time 1 were assessed as a means of estimating the experiences, positive versus negative, partners were capable of encountering over the course of their relationships.

\section{Materials}

Marital satisfaction. Most commonly used measures of marital satisfaction ask spouses to report their global sentiments toward the marriage as well as their level of agreement about specific problem areas (e.g., the Marital Adjustment Test; Locke \& Wallace, 1959). As several authors have pointed out (e.g., Fincham \& Bradbury, 1987), the use of such omnibus measures can lead to inflated associations with other variables that also address relationship processes. To ensure that global sentiments toward the relationship and level of agreement about specific relationship issues were not confounded in the current study and to ensure that any results were not idiosyncratic to a particular measure, two measures of satisfaction were used that assess global evaluations of the relationship exclusively. The first measure was a version of the Semantic Differential (SMD; Osgood, Suci, \& Tannenbaum, 1957), which asks spouses to rate their perceptions of their relationship on 7-point scales between fifteen pairs of opposing adjectives (e.g., bad-good, dissatisfied-satisfied, unpleasant-pleasant). The SMD yields scores from 15 to 105 . Higher scores reflect more positive satisfaction with the relationship. In the current sample, internal consistency of this measure was high (across the eight waves, coefficient alpha ranged from .91 to .97 for husbands and from .93 to .97 for wives). The second measure was the Quality Marriage Index (QMI; Norton, 1983), a six-item scale asking spouses to report the extent to which they agree or disagree with general statements regarding the quality of their marriage. Five items ask spouses to respond according to a 7-item scale, whereas one item asks spouses to respond according to a 10-item scale, yielding scores from 6 to 45. High scores reflect more positive satisfaction with the relationship. Internal consistency of this measure also was high in the current sample (across the eight waves, coefficient alpha ranged from .94 to .97 for husbands and from .94 to .98 for wives).

Expectations. Newlywed spouses are likely to have well-defined expectations for many aspects of their relationship. Because the current study was focused on expectations that could potentially serve as goals or as counterfactuals, it was important to examine expectations that were both (a) disconfirmable and (b) likely to vary across spouses. Based on these

${ }^{1}$ Other articles have been published using this data set: Frye and Karney (2002, in press), McNulty and Karney (2001, 2002), Neff and Karney (2002a, 2002b, 2003, 2004), and Vogel and Karney (2002). So far, however, this article is the only one to examine the effects of expectations for the relationship and expectations for the partner and the only one to examine eight waves of satisfaction data covering the first 4 years of marriage. 
criteria, two measures of expectations were developed for the current study.

Given that the primary dependent variable examined here was change in satisfaction over time, the first measure of expectations asked spouses to describe their expectations for how their relationships would change over time. Specifically, spouses were asked how their satisfaction was likely to vary over the course of the relationship. Consistent with recent evidence that variability in relationship satisfaction predicts long-term relationship stability (Arriaga, 2001), spouses were asked to describe whether they expected their satisfaction to vary considerably over time or whether they expected their satisfaction to remain fairly steady over time. Spouses responded to three items. The first item asked: "Over the next six months, which of the following describes how your feelings towards your marriage are likely to change?" with response possibilities of $1=$ major highs/major lows, 2 = some ups and downs, $3=a$ few ups and downs, $4=$ pretty steady, and $5=$ very steady. The second item asked the same question with respect to the "next four years." Finally, the third item asked spouses to select from among nine pictures reflecting different patterns of growth and variability the one pattern that best represented their expected trajectory of marital satisfaction over the upcoming 6 months. All pictures depicted various trajectories and various degrees of variability. Partners' selections were coded according to the degree of variability represented in the picture (e.g., 1 = some variability, $2=$ no variability). All three items were standardized and summed to form a single index with adequate internal consistency (coefficient $\alpha=.77$ for husbands and .78 for wives) and substantial between-subjects variability. Higher scores on this measure indicate more positive expectations: a tendency for spouses to expect greater steadiness in their satisfaction over time.

The second measure of expectations asked spouses to report their expectations for their partners in the relationship. Some spouses may hold extremely positive expectations for how their partners are likely to behave, expecting that their partners will be unfailingly sensitive and caring at every occasion. Others may hold less positive expectations, recognizing that their partners may fail or disappoint them at times. To capture between-spouse variability in these expectations, a nine-item measure was developed that asked spouses to rate their agreement with a series of statements (e.g., "My partner will rarely make mistakes," "My partner will agree with me about the important things," "My partner will always take time for me when I need him/her") on a scale from 1 (strongly disagree) to 7 (strongly agree; potential range $=7-63$ ). These items were summed to form a single index that was normally distributed and had adequate internal consistency (coefficient $\alpha=.71$ for husbands and .80 for wives) and substantial between-subjects variability. Higher scores on this measure indicate more positive expectations: a tendency for spouses to have more positive expectations for their partners' behaviors (the complete measure is presented in the Appendix).

Marital interaction behavior. The ability to behave positively in the marriage was estimated by coding the videotapes from Time 1 using a modified version of the Verbal Tactics Coding Scheme (Sillars, Coletti, Parry, \& Rogers, 1982). This version of the Verbal Tactics Coding Scheme assigns one of four possible codes to each speaking turn of each spouse. A speaker received an avoidant code for speaking turns that were off topic or moved the discussion away from the problem at hand. A speaker received one of two negative codes for speaking turns that either directly faulted, rejected, or criticized the partner (direct negative), or indirectly criticized the partner through presumptive attributions, avoiding responsibility, or hostile questions (indirect negative). A speaker received a constructive code for speaking turns that were on topic and furthered the resolution of the conflict.

The reliability of this system was assessed by randomly choosing $30 \%$ of the interactions to be coded by a second rater. Degree of agreement between raters was estimated with an intraclass correlation coefficient (ICC) comparing the amounts of each code observed by each rater across the interactions. ICCs indicated adequate interrater reliability for the codes analyzed in the current study (for direct negative, ICC $=.67$ for husbands and .83 for wives; for indirect negative, ICC $=.83$ for husbands and .65 for wives; for constructive, ICC $=.77$ for husbands and .87 for wives). Our hypotheses did not distinguish between types of behavior, so we combined the two negative codes and subtracted the positive code to arrive at an index of the net negativity expressed by each spouse during the interaction. The high correlations among the codes justified this procedure (absolute values ranged from $r=.40$ to $r=.73$ for husbands and from $r=.34$ to $r=.70$ for wives). Further, because our hypotheses did not distinguish between husbands' and wives' problem-solving topics, indices were further collapsed across both interactions (where behaviors were strongly correlated: $r=.49$ for husbands, $r=.34$ for wives). Finally, because both partners in a given interaction can create experiences that may confirm or disconfirm expectations, and because spouses' behaviors during the interaction were strongly correlated $(r=.57)$, the index was further collapsed across spouses, resulting in a single score that captured the nature of couples' observed skill at communicating about marital problems. ${ }^{2}$

Attributions. The ability to interpret events positively in the marriage was estimated using the Relationship Attributions Measure (Fincham \& Bradbury, 1992). This 24-item measure presents spouses with four negative stimulus events that are likely to occur in all marriages (e.g., "Your spouse criticizes something you say" and "Your spouse begins to spend less time with you"). For each event, spouses are asked to rate their agreement on a 7-point scale ranging from Agree strongly to Disagree strongly, with statements that reflect six attribution dimensions. The Causal Attributions subscale consists of 12 judgments ( 3 dimensions $\times 4$ stimulus events), and the Responsibility Attributions subscale consists of 12 judgments. For Causal Attributions, the three dimensions relate to the perceived locus, globality, and stability of the cause of the negative partner behavior. For Responsibility Attributions, the three dimensions capture the extent to which spouses consider their partner's behaviors intentional, selfishly motivated, and blameworthy. For each subscale, a composite score was computed by summing the 12 judgments, resulting in two scores for each spouse with possible ranges of 12 to 84 . The internal consistency of each subscale was relatively high (for Causal Attributions, coefficient $\alpha=.85$ for husbands and .73 for wives; for Responsibility Attributions, coefficient $\alpha=.89$ for husbands and .90 for wives). Responses were recoded so that higher scores indicate attributions that view the partner in a more positive light.

\section{Data Analysis}

Because we were interested in examining the effects of expectations on the development of marital satisfaction over time, the dependent variable in these analyses was the trajectory of marital satisfaction over the first 4 years of marriage. To estimate this trajectory for each spouse, we conducted growth curve analysis (GCA) using hierarchical linear modeling (HLM; Bryk \& Raudenbush, 1987, 1992) and the HLM/2L computer program (Bryk, Raudenbush, \& Congdon, 1994). This approach has several advantages. First, in contrast to other approaches to analyzing trajectories (e.g., structural equation modeling), HLM provides reliable estimates of within-subject parameters even when sample sizes are relatively small. Second, HLM provides maximally efficient estimates of these parameters by weighting individual estimates according to Bayes's theorem (Box \&

\footnotetext{
${ }^{2}$ Additional analyses examined the effects of negative and positive behavior as separate indices and treated husbands' behavior and wives' behavior as separate indices. Results from both additional analyses were consistent with the results reported for the index of couple-level behavior. Because avoidant behavior is categorically different from negative and positive behavior, and because we made no predictions regarding the moderating effect of avoidance on the association between expectations and satisfaction, avoidant codes were not examined in the current analyses.
} 
Tiao, 1973). When the within-subject parameter for an individual can be estimated precisely, the final estimate relies heavily on the individual data. When the parameter cannot be estimated precisely (e.g., because of missing data), the final estimate relies more heavily on the mean of the sample. Because the most precise estimates therefore contribute more to the final estimated variance of the sample, variances estimated in this way tend to be more conservative than those obtained through traditional ordinary least squares methods.

To test the hypothesis that behavior and relationship attributions interact with initial expectations to predict changes in satisfaction over time, two-stage growth curve analyses were conducted to model individual change over the eight assessments of each couple. In the first stage of these analyses, within-subjects trajectories were computed for each individual's marital satisfaction over time. In the second stage, the independent variables and their interactions were used to account for between-subjects differences in the parameters of these trajectories. To control for dependencies in partners' data, parameters describing husbands' and wives' trajectories were estimated simultaneously in a couple-level model, according to procedures described by Raudenbush, Brennan, and Barnett (1995).

\section{Results}

\section{Descriptive Statistics and Preliminary Analyses}

Of the 82 couples who responded at Time 1, 17 (21\%) were dissolved at Time 8 . Nevertheless, because HLM computed satisfaction slopes for all spouses who reported their satisfaction on at least three occasions, some of these dissolved couples were included in the current analyses, resulting in a relatively low rate of attrition. Whereas the average rate of retention in prior research on marriage is $69 \%$ (Karney \& Bradbury, 1995), all 65 nondissolved couples reported at Time 8, representing $80 \%$ of the sample. Furthermore, 12 dissolved couples reported their marital satisfaction on at least three occasions, allowing for longitudinal analyses to be based on 77 of the original 82 couples, or $94 \%$ of the sample. ${ }^{3}$

Descriptive statistics for all independent variables are reported in Table 1. As would be expected within a sample of newlyweds, on average husbands and wives held very positive expectations for their relationships and for their partners. Husbands and wives also tended to make relatively charitable attributions for their partners' negative behaviors, relieving their partners of blame and seeing external causes for negative events, and tended to exchange relatively high proportions of positive behaviors during their problemsolving interactions. Paired-sample $t$ tests revealed that no gender differences were significantly different from zero on any of the variables examined here.

Although, on average, expectations scores are quite positive, the positivity does not threaten the validity of the current study for two

Table 1

Descriptive Statistics for Independent Variables at Time 1

\begin{tabular}{lrrrrrr}
\hline & \multicolumn{2}{c}{ Husbands } & & \multicolumn{2}{c}{ Wives } \\
\cline { 2 - 3 } \cline { 6 - 7 } \multicolumn{1}{c}{ Measure } & $M$ & $S D$ & & $M$ & $S D$ \\
\hline Expectations for satisfaction steadiness & 9.0 & 2.1 & 9.1 & 2.1 \\
Expectations for partner's behaviors & 45.5 & 6.5 & 43.9 & 8.6 \\
Causality Attributions & 53.3 & 11.2 & & 51.4 & 9.9 \\
Responsibility Attributions & 63.6 & 12.1 & & 60.8 & 14.6 \\
Net positive behavior (\%) & 67.0 & 22.0 & & 67.0 & 22.0 \\
\hline
\end{tabular}

reasons. First, despite the positivity of these average scores, standard deviations reveal substantial variability in partners' reports. In fact, both measures of expectations are relatively normally distributed. Second, the central theme of this study is to examine whether the effects of expectations depend on whether they are likely to undergo processes of expectancy confirmation. Such expectancy confirmation depends, not on the valence of the expectations alone, but on comparisons between expectations and the experiences couples are likely to encounter given their relationship skills. Accordingly, even very positive expectations can be confirmed, and even very negative expectations can fail to be confirmed. Testing the current hypotheses requires examining the interactions between expectations and attributions and expectations and behavior.

Correlations among the independent variables are reported in Table 2. As expected, both measures of expectations were significantly correlated for each spouse. Additionally, consistent with previous work, each spouse's attributions for responsibility and attributions for causality were strongly correlated (Bradbury \& Fincham, 1990). Also, husbands' and wives' attribution scores were significantly positively associated with each measure of their expectations, indicating that spouses who tended to make positive attributions also tended to hold positive expectations for their relationships and for their partners. Observations of the positive behavior exhibited during the interactions demonstrated a significant positive correlation with wives' responsibility attributions, indicating that wives who tended to experience more positive behavior during their interactions also tended to relieve their husbands from blame for their negative behaviors. Observations of behavior were not significantly correlated with any additional wives' cognitions, and observations of behavior were not significantly correlated with any of the husbands' cognitions. Finally, between-spouse correlations are presented on the diagonal in Table 2. As can be seen, husbands' and wives' scores were significantly positively associated with one another on all measures except responsibility attributions. In sum, preliminary analyses reveal that all measures examined here are performing as expected.

\section{Describing the Trajectory of Satisfaction}

The mean scores for husbands and wives on each measure of marital satisfaction at each wave of data collection are presented in Table 3. As can be seen in Table 3, it appears that scores on both measures of marital satisfaction became less positive over time for both husbands and wives, suggesting a linear decline in satisfaction within these data. Within-subject change in satisfaction over time was assessed with GCA using HLM. The following model was assessed:

$$
Y_{\mathrm{ij}}=\beta_{0 \mathrm{j}}+\beta_{1 \mathrm{j}}(\text { Time })+\mathrm{r}_{\mathrm{ij}}
$$

where $Y_{\mathrm{ij}}$ is the marital satisfaction of Individual $\mathrm{j}$ at Time $\mathrm{i} ; \beta_{\mathrm{Oj}}$ is the marital satisfaction of Individual $\mathrm{j}$ at Time 0 (i.e., the initial satisfaction of Individual $\mathrm{j}$ ); $\beta_{1 \mathrm{j}}$ is the rate of linear change in

\footnotetext{
${ }^{3}$ Subsequent analyses, including a dummy variable to represent relationship status, revealed that the effects described in the current study remained significant controlling for relationship dissolution.
} 
Table 2

Correlations Among Independent Variables at Time 1

\begin{tabular}{llllll}
\hline \multicolumn{1}{c}{ Measure } & 1 & 2 & 3 & 4 & 5 \\
\hline \multicolumn{7}{c}{ Expectations } \\
1. Expectations for steadiness &. $\mathbf{3 5} *$ & $.36^{* *}$ & $.24^{*}$ & $.24^{*}$ & -.04 \\
2. Expectations for partner & $.33^{* *}$ & $.5^{* *}$ & $.27^{*}$ & $.29^{* *}$ & -.08 \\
\hline \multicolumn{7}{c}{ Moderators } \\
3. Causality Attributions & $.26^{*}$ & $.34^{* *}$ & $.25^{*}$ & $.62^{* *}$ & -.06 \\
4. Responsibility Attributions & $.31^{* *}$ & $.22^{*}$ & $.56^{* *}$ & $\mathbf{. 0 9}$ & -.03 \\
5. Positive behavior & .16 & .03 & .07 & $.36^{* *}$ & - \\
\hline
\end{tabular}

Note. Correlations between husbands and wives appear in boldface type. Husbands' correlations are above those in boldface; wives' correlations are below.

$* p<.05 . \quad * * p<.01$, two-tailed.

marital satisfaction of Individual $\mathrm{j}$; and $\mathrm{r}_{\mathrm{ij}}$ is the residual variance in repeated measurements for Spouse $\mathrm{j}$, assumed to be independent and normally distributed across spouses. This model can be understood as a within-subjects regression of an individual's marital satisfaction score onto time of assessment, where time was defined as the wave of data collection. The model was applied separately to each measure of marital satisfaction but simultaneously to husbands' and wives' data, using procedures described by Raudenbush et al. (1995).

Fitting the model to these data provided generalized least squares estimates of the average intercept and slope of marital satisfaction for husbands and wives as well as restricted maximum-likelihood estimates of the variances of these parameters. These estimates are reported in Table 4 along with $t$ statistics that test whether the means of each parameter are different from zero and chi-square statistics that test whether the variances of each parameter are different from zero. With respect to the intercept, the estimates presented in Table 4 confirm that on average husbands and wives reported relatively high initial levels of marital satisfaction. Comparison of Table 4 with Table 3 reveals that the mean intercept for each measure is similar to the mean satisfaction reported at Time 1. This is to be expected, because the intercept represents the starting point of the trajectory. However, as revealed by the chi-square tests of variance, the mean initial satisfaction varied significantly across husbands and across wives on both measures of marital satisfaction. In other words, even at the outset of the marriage, some spouses were significantly happier than others.

With respect to the slope, the estimates presented in Table 4 confirm that on average, husbands and wives tended to experience significant declines in satisfaction over the first 4 years of marriage, consistent with prior studies of marital satisfaction (e.g., Karney \& Bradbury, 1997). The $t$ statistics reported in Table 4 reveal significant negative trajectories for husbands and wives on both measures of marital satisfaction. Furthermore, according to the significance of the chi-square tests reported in Table 4, the trajectories varied significantly across wives and marginally significantly across husbands for both measures. In other words, although on average husbands' and wives' satisfaction declined over the first 4 years of marriage, satisfaction declined more for some spouses than it did for others. ${ }^{4}$

\section{Were Expectations Associated With Change in Satisfaction Over Time?}

Before addressing central hypotheses of this study involving interactions, preliminary analyses were conducted to determine the main effects of expectations on change in satisfaction. These analyses ignore the cognitive and behavioral abilities of spouses to ask whether there are overall effects on the trajectory of having more or less positive expectations at the outset of a marriage. To address this question, each measure of expectations was entered into the second stage of the HLM analysis to account for betweensubjects variability in the parameters estimated by Equation 1. The top half of Table 5 reports the associations between expectations and initial satisfaction. The $t$ statistics in this section reveal a consistent pattern of significant positive associations between expectations and initial marital satisfaction, with one marginally significant association between wives' expectations for satisfaction steadiness and initial scores on the QMI. Not surprisingly, spouses who were initially more satisfied with the relationship tended to hold more positive expectations about their relationships and about their partners. Of note, although the association between initial satisfaction and expectations for partner's behavior was significant for husbands and for wives, it was significantly stronger for husbands than for wives on the SMD, $\chi^{2}(1, N=80)=3.8$, $p<.05$.

The associations between expectations and the slope of marital satisfaction, controlling for associations between expectations and the intercept, are reported in the bottom half of Table 5. As these associations reveal, once the cross-sectional association between expectations and initial satisfaction was controlled, expectations rarely demonstrated significant associations with change in satisfaction over time. The one significant association was that husbands' expectations for their wives' behavior was significantly negatively associated with change in satisfaction over time as measured on the SMD, such that husbands who had more positive expectations on average experienced steeper declines in their satisfaction over time. Aside from this effect, however, neither type of expectation was significantly associated with change in satisfaction over time for husbands or wives on either measure of marital satisfaction.

\section{Do Behaviors or Relationship Attributions Moderate the Effects of Expectations on Change in Marital Satisfaction?}

The primary goal of the current study was to examine whether the effects of positive expectations on changes in satisfaction are moderated by behavior and attributions. The previous analyses revealed that on average neither type of expectation was consistently associated with changes in relationship satisfaction over time in the current sample. Nevertheless, it remains possible that

\footnotetext{
${ }^{4}$ These data were also examined for the presence of nonlinear (i.e., quadratic) changes in marital satisfaction over time. A quadratic model of change provided a significantly worse fit to these data.
} 
Table 3

Mean Marital Quality Scores Across Eight Waves of Measurement for Husbands and Wives

\begin{tabular}{|c|c|c|c|c|c|c|c|c|}
\hline Spouse & Time 1 & Time 2 & Time 3 & Time 4 & Time 5 & Time 6 & Time 7 & Time 8 \\
\hline \multicolumn{9}{|c|}{ Semantic Differential } \\
\hline \multicolumn{9}{|l|}{ Husbands } \\
\hline$M$ & 96.3 & 92.0 & 92.5 & 92.1 & 93.5 & 92.1 & 91.1 & 92.8 \\
\hline$S D$ & 8.8 & 14.1 & 14.8 & 14.7 & 13.9 & 15.5 & 19.9 & 12.7 \\
\hline$N$ & 81 & 76 & 74 & 67 & 64 & 59 & 60 & 66 \\
\hline \multicolumn{9}{|l|}{ Wives } \\
\hline$M$ & 97.7 & 94.8 & 93.3 & 92.1 & 93.8 & 90.0 & 89.1 & 92.1 \\
\hline$S D$ & 10.7 & 12.9 & 16.0 & 14.7 & 15.6 & 19.3 & 19.6 & 17.5 \\
\hline$N$ & 82 & 77 & 73 & 68 & 66 & 60 & 62 & 65 \\
\hline
\end{tabular}

Quality Marriage Index

\begin{tabular}{ccccccccc} 
Husbands & & & & & & & & \\
$M$ & 42.1 & 40.3 & 40.3 & 40.1 & 40.8 & 40.2 & 38.9 & 40.2 \\
$S D$ & 4.0 & 6.7 & 6.6 & 7.0 & 6.5 & 6.5 & 8.4 & 6.0 \\
$N$ & 81 & 76 & 74 & 67 & 64 & 59 & 60 & 66 \\
Wives & & & & & & & & \\
$M$ & 42.1 & 40.8 & 39.9 & 39.0 & 40.2 & 38.3 & 38.3 & 39.3 \\
$S D$ & 5.3 & 6.0 & 7.5 & 8.6 & 7.3 & 9.4 & 9.1 & 8.2 \\
$N$ & 82 & 77 & 73 & 68 & 66 & 61 & 62 & 65 \\
\hline
\end{tabular}

Note. Means using only participants reporting at Time 8 are similar and demonstrate similar trends.

when partners' positive expectations were likely to be confirmed by their experiences, either because of a tendency to engage in more positive behaviors or a tendency to make positive attributions, they did predict more stable satisfaction over time. In contrast, when spouses' positive expectations were unlikely to be confirmed by their experiences, either because of a tendency to engage in more negative behaviors or a tendency to make negative attributions, it remains possible that they predicted declines in

Table 4

Change in Marital Satisfaction

\begin{tabular}{|c|c|c|c|c|}
\hline Measure & $M$ & $S D$ & $t(81)^{\mathrm{a}}$ & $\chi^{2}(1, N=81)$ \\
\hline \multicolumn{5}{|c|}{ Intercept } \\
\hline \multicolumn{5}{|l|}{ SMD } \\
\hline Husbands & 95.2 & 1.1 & - & 181.9 *** \\
\hline Wives & 97.3 & 1.3 & - & $238.5 * * *$ \\
\hline \multicolumn{5}{|l|}{ QMI } \\
\hline Husbands & 41.7 & 0.52 & - & $170.3 * * *$ \\
\hline Wives & 41.8 & 0.56 & - & $195.0 * * *$ \\
\hline \multicolumn{5}{|c|}{ Slope } \\
\hline \multicolumn{5}{|l|}{ SMD } \\
\hline Husbands & -0.64 & 0.16 & $-3.9 * * *$ & $100.9 \dagger$ \\
\hline Wives & -1.06 & 0.21 & $-5.2 * * *$ & $160.2 * * *$ \\
\hline \multicolumn{5}{|l|}{ QMI } \\
\hline Husbands & -0.35 & 0.08 & $-4.4 * * *$ & $98.2 \dagger$ \\
\hline Wives & -0.49 & 0.09 & $-5.3 * * *$ & $133.2 * * *$ \\
\hline \multicolumn{5}{|c|}{$\begin{array}{l}\text { Note. SMD = Semantic Differential (Osgood et al., 1957); QMI = } \\
\text { Quality Marriage Index (Norton, 1983). } \\
\text { a The } t \text { test of the intercepts addresses the hypothesis that the intercepts } \\
\text { differ significantly from zero. Because the lowest possible score on each of } \\
\text { these measures is greater than zero, these tests are not meaningful and } \\
\text { hence are not reported. } \\
\dagger p<.10 \text {. *** } p<.001 \text {, one-tailed. }\end{array}$} \\
\hline
\end{tabular}

satisfaction. To examine these possibilities, each measure of expectations and each potential moderator were centered and entered separately into a second-stage analysis, along with the appropriate interaction term, to account for between-subjects variability in within-subject change in satisfaction as estimated in Equation 1.

The results of the analyses regarding the interactions between expectations and behavior on change in satisfaction are reported in the first two columns of Table 6. The effect sizes in these two columns reveal a pattern of significant negative interactions between wives' expectations for their husbands' behavior and the

Table 5

Effects of Expectations on the Trajectory of Marital Satisfaction

\begin{tabular}{|c|c|c|c|c|}
\hline \multirow[b]{2}{*}{ Expectations } & \multicolumn{2}{|c|}{ Husband } & \multicolumn{2}{|c|}{ Wife } \\
\hline & $t(80)$ & $d$ & $t(80)$ & $d$ \\
\hline \multicolumn{5}{|c|}{ Satisfaction intercepts } \\
\hline \multicolumn{5}{|c|}{ For satisfaction steadiness } \\
\hline SMD & $2.83 * *$ & $0.30 * *$ & $2.63 * *$ & $0.28^{* *}$ \\
\hline QMI & $2.06^{*}$ & $0.23 *$ & $1.66 \dagger$ & $0.17 \dagger$ \\
\hline \multicolumn{5}{|c|}{ For partner's behaviors } \\
\hline SMD & $4.48 * * *$ & $0.45^{* * *}$ & $2.20 *$ & $0.24 *$ \\
\hline QMI & $3.47 * * *$ & $0.36^{* *}$ & $2.04 *$ & $0.22^{*}$ \\
\hline \multicolumn{5}{|c|}{ Satisfaction slopes } \\
\hline \multicolumn{5}{|c|}{ For satisfaction steadiness } \\
\hline SMD & 0.09 & 0.01 & -0.97 & -0.11 \\
\hline QMI & 0.53 & 0.06 & -0.46 & -0.05 \\
\hline \multicolumn{5}{|c|}{ For partner's behaviors } \\
\hline SMD & $-3.57 * *$ & $-0.37 * *$ & -0.72 & -0.08 \\
\hline QMI & -1.37 & -0.15 & -0.05 & -0.01 \\
\hline
\end{tabular}

Note. $\quad$ SMD $=$ Semantic Differential (Osgood et al., 1957); QMI = Quality Marriage Index (Norton, 1983).

$\dagger p<.10 . \quad * p<.05 . \quad * * p<.01 . \quad * * * p<.001$, one-tailed. 
Table 6

Moderating Effects of Positive Behavior and Attributions on the Association Between Expectations and the Trajectory of Satisfaction

\begin{tabular}{|c|c|c|c|c|c|c|}
\hline \multirow[b]{2}{*}{ Expectations } & \multicolumn{2}{|c|}{ Positive behavior } & \multicolumn{2}{|c|}{$\begin{array}{l}\text { Responsibility } \\
\text { attributions }\end{array}$} & \multicolumn{2}{|c|}{$\begin{array}{c}\text { Causality } \\
\text { attributions }\end{array}$} \\
\hline & Husband & Wife & Husband & Wife & Husband & Wife \\
\hline \multicolumn{7}{|c|}{ For satisfaction steadiness } \\
\hline SMD & -0.01 & -0.13 & $0.23 *$ & $0.32 * *$ & $0.22 *$ & $0.28 * *$ \\
\hline QMI & -0.05 & -0.15 & $0.24 *$ & $0.18 \dagger$ & 0.09 & 0.07 \\
\hline \multicolumn{7}{|c|}{ For partner's behaviors } \\
\hline SMD & -0.02 & $-0.32^{* *}$ & $0.20 *$ & $0.35^{* * *}$ & $0.28 * *$ & $0.19 *$ \\
\hline QMI & -0.09 & $-0.35^{* * *}$ & $0.22 *$ & $0.35^{* * * *}$ & $0.29 * *$ & $0.18 \dagger$ \\
\hline
\end{tabular}

Note. $\quad$ SMD $=$ Semantic Differential (Osgood et al., 1957); QMI = Quality Marriage Index (Norton, 1983).

$\dagger p<.10 . \quad * p<.05 . \quad * * p<.01 . \quad * * * p<.001$, one-tailed

proportions of positive behavior observed in the relationship on changes in their satisfaction over time. To determine the nature of these interactions, they were deconstructed by substituting values one standard deviation above the mean and one standard deviation below the mean into the regression equation and plotting the predicted outcomes (see Aiken \& West, 1991; Cohen \& Cohen, 1983). The resulting plots revealed the same pattern of interactions across all significant interactions. A representative sample of these plots is depicted in Figure 1. Figure 1 depicts the interactive effects of positive behavior and wives' expectations for their husbands' behaviors on change in satisfaction on the QMI. Consistent with predictions, this figure illustrates that when behavior was the most positive at the outset of the marriage, more positive expectations predicted the most stable satisfaction and less positive expectations predicted steeper declines in satisfaction over the subsequent 4 years. In contrast, when behavior was least positive at the outset of the marriage, more positive expectations predicted steeper declines in marital satisfaction whereas less positive expectations predicted more stable satisfaction. Of note, although the interactions were significant for wives but not husbands, none of the gender differences were significantly different from zero.

The results of the analyses regarding the interactions between expectations and attributions are reported in the last four columns

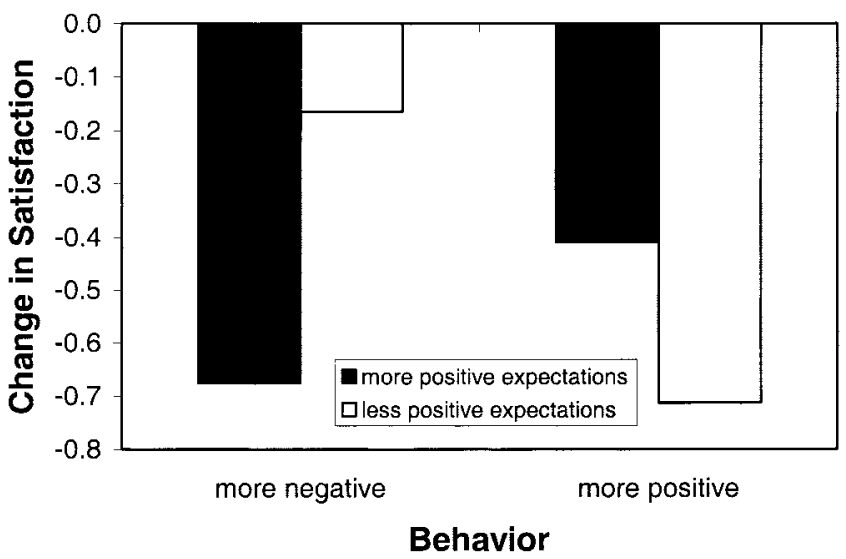

Figure 1. Moderating effects of behavior on the association between expectations and the trajectory of marital satisfaction. of Table 6. The effect sizes in these columns reveal a pattern of significant positive interactions for both wives and husbands. To determine the nature of these interactions, they were deconstructed in the same manner as the previous interactions. Again, these plots revealed the same pattern of interactions across all significant interactions. Samples of these plots are presented in Figures 2 and 3. To illustrate that the pattern of results is robust across different measures and across gender, each figure depicts a different measure of expectations, a different measure of satisfaction, and a different gender. Thus, Figure 2 depicts the interactive effects of wives' responsibility attributions and their expectations for steadiness in the relationship on change in satisfaction on the SMD, and Figure 3 depicts the interactive effects of husbands' causality attributions and their expectations for their wives' behaviors on change in satisfaction on the QMI. Consistent with predictions, these figures illustrate that when attributions were more positive at the outset of the marriage, more positive expectations predicted more stable satisfaction, and less positive expectations predicted steeper declines in satisfaction over the subsequent 4 years. In contrast, when attributions were least positive at the outset of the marriage, more positive expectations predicted steeper declines in marital satisfaction, whereas less positive expectations predicted more stable satisfaction. Again, although some interactions were significant for wives but not husbands, none of the gender differences in these effects were significantly different from zero.

\section{Discussion}

\section{Rationale and Summary of Results}

Given that expectations influence a wide variety of interpersonal phenomena (Olson, Roese, \& Zanna, 1998), the initially positive expectations that partners have for their intimate relationships should have implications for the development of those relationships over time. Prior literature on the effects of positive expectations confirms this idea but offers competing descriptions of the nature of this effect. When they function as goal structures, positive expectations appear to be beneficial because they inspire perceptual and behavioral confirmation processes that in turn lead to positive outcomes. When they function as counterfactuals, however, positive expectations can be detrimental because partners may be disappointed when their expectations are not met. The 


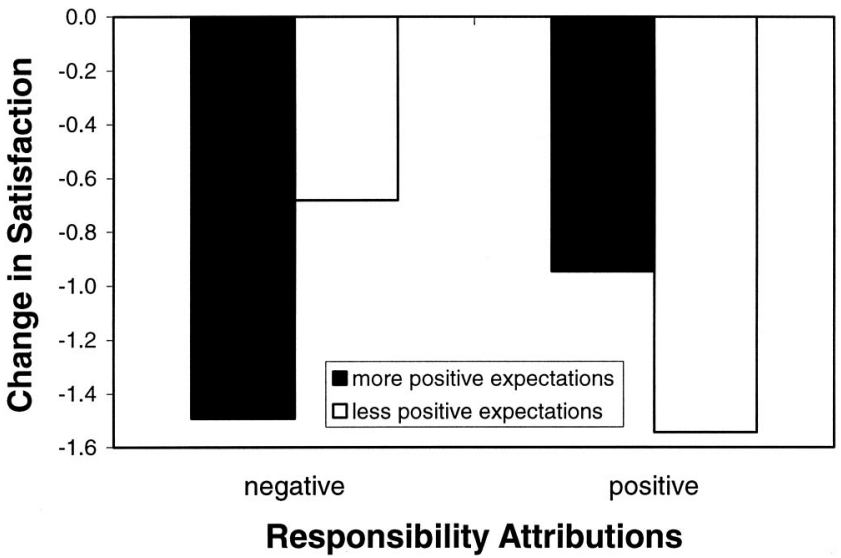

Figure 2. Moderating effects of husbands' responsibility attributions on the association between expectations and the trajectory of marital satisfaction.

current study examined the possibility that the ability to behave constructively and the ability to make positive attributions may be two factors that determine which role expectations play in the evaluation process and therefore may moderate the effects of positive expectations on changes in relationship satisfaction. Specifically, positive expectations should be beneficial when partners' ability to behave constructively or make charitable attributions enables their expectations to function as goals that can be achieved through processes of expectancy confirmation. For these couples, less positive expectations may be a liability because they do not allow couples to take advantage of the skills they possess. In contrast, positive expectations may prove harmful for partners whose weaker ability to behave positively or make charitable attributions makes it more likely that their expectations will serve as counterfactuals and lead to disappointments. For these couples, less positive expectations may be more beneficial because they may serve as less severe contrasts to actual outcomes.

Preliminary analyses revealed that although spouses' expectations were positively associated with their initial marital satisfaction, on average they had few significant main effects on changes in satisfaction over time. Consistent with predictions, however, longitudinal effects of positive expectations did emerge in interactions with marital behavior and attributions. With respect to attributions, the patterns of these interactions were robust across spouses and across different measures of expectations and satisfaction. When attributions were most positive, more positive expectations predicted more stable satisfaction, whereas less positive expectations predicted steeper declines in satisfaction. In contrast, when attributions were most negative, more positive expectations predicted steeper declines in marital satisfaction, whereas less positive expectations predicted more stable satisfaction. With respect to marital behavior, the patterns of interactions arose for wives' expectations for husbands' behavior but not for husbands' expectations for wives' behavior. When relationship behaviors were most positive, wives' more positive expectations for their husbands' behaviors predicted more sta- ble satisfaction, whereas their less positive expectations for their husbands' behaviors predicted steeper declines in satisfaction. In contrast, when behaviors were most negative, wives' more positive expectations for husbands' behaviors predicted steeper declines in marital satisfaction, whereas their less positive expectations for husbands' behaviors predicted more stable satisfaction. In sum, which expectations are adaptive depends on the relationship context. When the relationship context is positive, positive expectations appear to be adaptive. When the relationship context is less positive, less positive expectations appear to be adaptive.

It may seem counterintuitive that spouses who entered their relationships with positive abilities but less positive expectations experienced steeper declines in their relationship satisfaction. After all, both DAT and interdependence theory predict that these people should be pleasantly surprised by the positive outcomes that their skills should provide. Nevertheless, the current results are consistent with predictions. Such spouses may have been less likely to put forth the effort to take advantage of their skills throughout the remainder of their relationships because they lacked the positive expectations that would motivate such effort. Therefore, their more moderate expectations prevented them from achieving positive experiences.

It is also important to note that although partners who lacked relationship skills and possessed less positive expectations for their relationships appear to have experienced the most stable satisfaction over time, the level of satisfaction for these couples was not as high as it was for couples who possessed more positive skills. Rather, expectations were positively associated with initial satisfaction in the current study, suggesting that partners in this sample who began their marriages with low expectations and poor skills were less stably happy over the first years of their marriages. Nevertheless, these partners did benefit from their less positive expectations relative to partners with low skills and more positive expectations, demonstrating the potential benefits of less positive expectations for partners who are likely to encounter negative experiences over the course of their relationships.

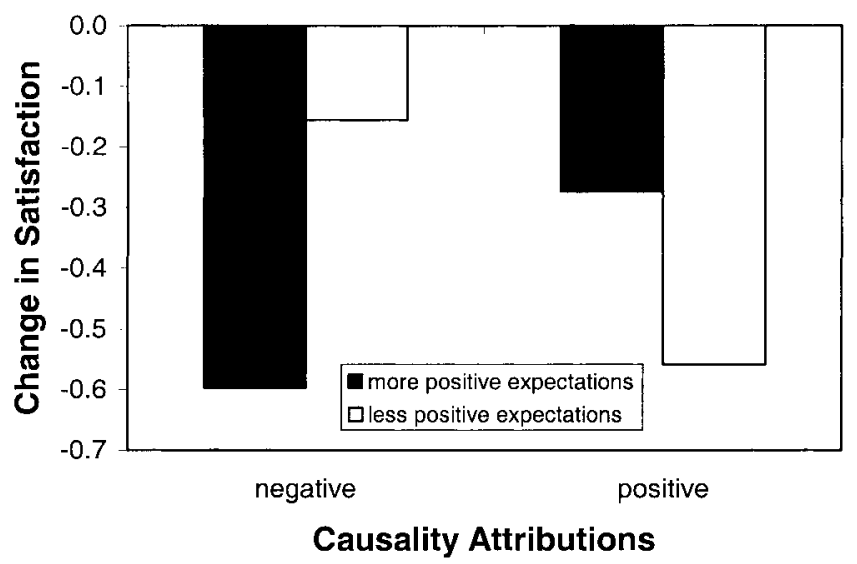

Figure 3. Moderating effects of wives' causality attributions on the association between expectations and the trajectory of marital satisfaction. 


\section{Theoretical and Applied Implications}

The current findings have several implications for research on close relationships. First, they contribute to debates about whether accurate beliefs or positively biased beliefs are more beneficial for relationship functioning (Armor \& Taylor, 1998; Baumeister, 1989; Murray \& Holmes, 1997; Murray, Holmes, \& Griffin, 1996a; Radcliffe \& Klein, 2002; Robins \& Beer, 2001; Swann, 1990; Taylor \& Brown, 1994; Wiebe \& Black, 1997). Although a number of studies have demonstrated the benefits of positively biased beliefs about relationships, the current findings offer two potential boundary conditions of these benefits. First, the current findings suggest that the benefits of positive bias may be limited to the short term. Much of the research on the benefits of positive bias has demonstrated such benefits over a relatively short period of time. Consistent with this research, in the current study positive expectations about the relationship were cross-sectionally associated with positive relationship satisfaction. Nevertheless, over an interval of 4 years, positive expectations were more beneficial to the extent that they were realistic (i.e., held by partners who possessed the skills to confirm them) and predicted steeper declines in relationship satisfaction to the extent that they were less realistic (i.e., held by partners who lacked sufficient relationship skills to confirm them; for related discussions, see Radcliffe \& Klein, 2002; Robins \& Beer, 2001; Wiebe \& Black, 1997). Second, the current findings suggest that the benefits of positive bias may be more evident for beliefs about global, ambiguous qualities. Whereas work demonstrating the benefits of positive bias in relationships typically has addressed relatively global perceptions of the partner (e.g., my partner is kind; Murray \& Holmes, 1997; Murray et al., 1996a), the current work demonstrated no such benefits for unrealistically positive expectations regarding aspects of a relationship that are less open to interpretation (e.g., my partner will always get along well with my parents; for related discussions, see Alicke, Klotz, Breitenbecher, \& Yurak, 1995; Dunning, 1995; Dunning \& McElwee, 1995; Dunning, Meyerowitz, \& Holzberg, 1989; Hampson, Goldberg, \& John, 1987; Hampson, John, \& Goldberg, 1986; Karney, McNulty, \& Bradbury, 2001; Karney, McNulty, \& Frye, 2001; McNulty \& Karney, 2001). In sum, whereas it appears beneficial for partners to maintain positive views of the more global qualities of their partners and relationships, the current study suggests that over the long term it is important for partners to have accurate knowledge of their relationship's specific strengths and weaknesses as well (for related discussions, see Neff \& Karney, 2002a, 2002b).

A second implication of these results is that they may reveal a common mechanism through which relationship cognitions influence relationship functioning. In contrast to the idea that positive expectations exert main effects on relationship outcomes, the current findings suggest that the effects of expectations may depend on whether couples' experiences confirm or disconfirm those expectations. Likewise, the effects of other relationship cognitions (e.g., beliefs, values, standards, etc.; see Karney, McNulty, \& Bradbury, 2001) may similarly influence relationships by interacting with the specific experiences that partners encounter over the course of their relationships. Several lines of research provide support for this idea (Eidelson \& Epstein, 1982; Epstein \& Eidelson, 1981; Fletcher et al., 2000; Helgeson, 1994; Jones \& Stanton, 1988; Swann, de la Ronde, \& Hixon, 1994). For example, as discussed above, research by Fletcher et al. (2000) demonstrated that the benefits of positive relationship standards depended on whether they were confirmed or disconfirmed. When ideal standards for the relationship were held and met, they were associated with higher levels of relationship satisfaction. When such standards were held but not met, however, they were associated with lower levels of relationship satisfaction. Similarly, in research on couples in long-distance dating relationships, positive beliefs about the relationship were beneficial to coping, but only when the couples stayed together (Helgeson, 1994). When positive beliefs about the relationship were disconfirmed by relationship dissolution, they led to greater levels of distress. Future research may benefit from examining the potential that other relationship cognitions may similarly interact with specific experiences to influence relationship outcomes.

Finally, the current findings have implications for interventions designed to alleviate or prevent marital distress. To the extent that the effects of expectations on relationship outcomes are moderated by qualities of the relationship, general advice about expectations may not apply equally well to all couples. Positive expectations are not harmful for everyone, nor are they beneficial for everyone. Instead, when advising clients about what to expect from the future, therapists might consider whether positive expectations will function as goals, likely to be confirmed by processes of expectancy confirmation, or as counterfactuals, likely to lead to disappointment. Spouses who possess the skills necessary to confirm positive expectations may benefit from fostering and maintaining positive expectations about their likelihood for future relationship success. For such individuals, positive expectations may inspire them to persist in resolving problems that may arise and view even negative experiences in a positive light. In contrast, couples who lack these skills or who are otherwise at risk to encounter negative experiences that will disconfirm positive expectations may benefit from moderating excessively positive expectations for their future outcomes. Such couples may respond more favorably to their negative experiences when they are expected rather than unexpected.

\section{Additional Directions for Future Research}

Where do unrealistically positive expectations come from? One source may be personality. For instance, recent work has demonstrated an association between depressive personality disorder and perfectionism (Huprich, 2003). It has been proposed that people with depressive personalities may try to gain acceptance from others by trying to avoid mistakes (Huprich, 2003). Given this possibility, and given that partners who experience higher levels of depression in their relationships tend to be less happy in those relationships (see O'Mahen, Beach, \& Banawan, 2001), it may be that unrealistically positive standards mediate the effects of depression on declines in relationship satisfaction. That is, depressed individuals may be less satisfied with their relationships because they hold standards for those relationships that are too high. In contrast to this idea, others have argued that depression is linked to more pessimistic expectations (e.g., Isaacowitz \& Seligman, 2001; Roberts, Roberts, \& Chen, 2000), suggesting that the effects of depression on declines in relationship satisfaction may be mediated by more negative expectations. Additional research is re- 
quired to tease apart the precise role of expectations in mediating the effects of personality variables on relationship functioning.

\section{Strengths and Limitations}

Our confidence in the findings reported here is enhanced by several strengths of this research. First, the general pattern of results was replicated across conceptually distinct measures of expectations and conceptually distinct measures of disconfirmation, suggesting that results were not unique to one construct or one method of measurement. Second, whereas the average rate of retention in prior research on marriage is 69\% (Karney \& Bradbury, 1995), analyses in the current study were able to use data from $94 \%$ of the initial sample, reducing the likelihood that the results were affected by attrition bias. Third, all spouses entering the study were newlyweds. Thus, although partners are likely to adjust their expectations as a result of experience (e.g., Fletcher et al., 2000), participants in the current study were less likely to have adopted expectations that completely overlapped with experiences, allowing for the possibility that expectations would be disconfirmed (Jussim \& Eccles, 1995; see also Booth, Johnson, White, \& Edwards, 1985; South \& Spitze, 1986). Fourth, the current study assessed expectations during a phase in which expectations are likely to be most critical: the beginning of the relationship. This phase of the relationship is likely to be a time when expectations for the marriage are just forming and thus are least likely to measure up to the realities that couples encounter. Fifth, whereas the majority of longitudinal research on marriage has collected and analyzed only two waves of data, the current analyses examined eight waves of data and analyzed all waves simultaneously using GCA.

Despite these strengths, several factors nevertheless limit interpretations of the current findings. First, whereas the homogeneity of this sample enhances our confidence in the pattern of associations, generalizations to other samples should be made with caution. For example, although the expectations spouses have in the beginning of their relationships appear to influence the later development of those relationships, the expectations of more established couples may more accurately reflect prior experience (see Jussim \& Eccles, 1995). If so, then the early years of marriage may be a unique period of relationship adjustment during which expectations are particularly important. Additional research may benefit by examining this possibility. Second, the homogeneity of the sample also limited the range of expectations assessed in the current study. Because all couples assessed in the current study were newlyweds, very few held expectations for their relationships that could be described as negative. Research examining a wider range of expectations may yield effects different from those obtained in the current study. For instance, although the current study revealed that more moderate expectations were more adaptive than very positive expectations for couples likely to experience negative outcomes, it is unlikely that truly negative expectations would also be adaptive for the relationship. Instead, negative expectations may lead couples to abandon their efforts to resolve relationship problems, leading to the eventual dissolution of the relationship (see Knee, 1998). Third, although the sample size in this study compared favorably with other longitudinal studies of marriage, a larger sample size would have provided greater power to detect additional effects not detected in the current study (e.g., gender differences).

\section{Conclusion}

Who was correct about the effects of positive expectations: Peale (1952), who suggested that positive expectations should lead to positive outcomes, or Pope (as cited in Bartlett \& Dole, 1919/ 2000), who argued that positive outcomes may lead to disappointment? Results of the current study suggest that within the context of close relationships, the answer may depend on various factors associated with relationship functioning. Consistent with Peale's view, spouses who have the skills to attain positive outcomes benefit from positive expectations. Consistent with Pope's view, spouses who lack the skills to cultivate positive experiences may benefit from more moderate expectations. Given that the benefits and costs of positive expectations depend on other relationship factors, the effects of other cognitive variables on long-term relationship outcomes may similarly depend on how those cognitions interact with the experiences couples are likely to encounter.

\section{References}

Aiken, L. S., \& West, S. G. (1991). Multiple regression: Testing and interpreting interactions. Newbury Park, CA: Sage.

Alicke, M. D., Klotz, M. L., Breitenbecher, D. L., \& Yurak, T. J. (1995). Personal contact, individuation, and the better-than-average effect. Journal of Personality and Social Psychology, 68, 804-825.

Armor, D. A., \& Taylor, S. E. (1998). Situated optimism: Specific outcome expectations and self-regulation. In M. P. Zanna (Ed.), Advances in experimental social psychology (Vol. 30, pp. 309-379). New York: Academic Press.

Arriaga, X. B. (2001). The ups and downs of dating: Fluctuations in satisfaction in newly formed romantic relationships. Journal of Personality and Social Psychology, 80, 754-765.

Bartlett, J. (Compiler), \& Dole, N. H. (Ed.). (2000). Familiar quotations (10th ed. rev.). Boston: Little, Brown. Retrieved February 23, 2004, from www.bartleby.com/100/ (Original work published 1919)

Baucom, D. H., Epstein, N., Rankin, L. A., \& Burnett, C. K. (1996). Assessing relationship standards: The Inventory of Specific Relationship Standards. Journal of Family Psychology, 10, 72-88.

Baumeister, R. F. (1989). The optimal margin of illusion. Journal of Social and Clinical Psychology, 8, 176-189.

Booth, A., Johnson, D. R., White, L. K., \& Edwards, J. N. (1985). Predicting divorce and permanent separation. Journal of Family Issues, 6, 331-346.

Box, G. E. P., \& Tiao, G. C. (1973). Bayesian inference in statistical analysis. Reading, MA: Addison-Wesley.

Bradbury, T. N., \& Fincham, F. D. (1990). Attributions in marriage: Review and critique. Psychological Bulletin, 107, 3-33.

Bryk, A. S., \& Raudenbush, S. W. (1987). Application of hierarchical linear models to assessing change. Psychological Bulletin, 101, 147158.

Bryk, A. S., \& Raudenbush, S. W. (1992). Hierarchical linear models. Applications and data analysis methods. Newbury Park, CA: Sage.

Bryk, A. S., Raudenbush, S. W., \& Congdon, R. T. (1994). HLM: Hierarchical linear modeling with the HLM/2L and HLM/3L programs [Computer software]. Chicago: Scientific Software International.

Cohen, J., \& Cohen, P. (1983). Applied multiple regression: Correlational analysis for the behavioral sciences (2nd ed.). Hillsdale, NJ: Erlbaum.

D’Angelo, C., \& Karney, B. R. (1999, March). A comparison between sampling methods in marital research. Paper presented at the annual meeting of the Southeastern Psychological Association, Savannah, GA. 
Darley, J. M., \& Fazio, R. H. (1980). Expectancy confirmation processes arising in the social interaction sequence. American Psychologist, 35, 867-881.

Darley, J. M., \& Gross, P. H. (1983). A hypothesis-confirming bias in labeling effects. Journal of Personality and Social Psychology, 44, $20-33$.

Downey, G., Freitas, A. L., Michaelis, B., \& Khouri, H. (1998). The self-fulfilling prophecy in close relationships: Rejection sensitivity and rejection by romantic partners. Journal of Personality and Social Psychology, 75, 545-560.

Dunning, D. (1995). Trait importance and modifiability as factors influencing self-assessment and self-enhancement motives. Personality and Social Psychology Bulletin, 21, 1297-1306.

Dunning, D., \& McElwee, R. O. (1995). Idiosyncratic trait definitions: Implications for self-description and social judgment. Journal of Personality and Social Psychology, 68, 936-946.

Dunning, D., Meyerowitz, J. A., \& Holzberg, A. D. (1989). Ambiguity and self-evaluation: The role of idiosyncratic trait definitions in self-serving assessments of ability. Journal of Personality and Social Psychology, 57, 1082-1090

Eidelson, R. J., \& Epstein, N. (1982). Cognition and relationship maladjustment: Development of a measure of dysfunctional relationship beliefs. Journal of Consulting and Clinical Psychology, 50, 715-720.

Epstein, N., \& Eidelson, R. J. (1981). Unrealistic beliefs of clinical couples: Their relationship to expectations, goals, and satisfaction. American Journal of Family Therapy, 9, 13-22.

Fincham, F. D., \& Bradbury, T. N. (1987). The assessment of marital quality: A reevaluation. Journal of Marriage and the Family, 49, 797809.

Fincham, F. D., \& Bradbury, T. N. (1992). Assessing attributions in marriage: The Relationship Attribution Measure. Journal of Personality and Social Psychology, 62, 457-468.

Fletcher, G. J. O., Simpson, J. A., \& Thomas, G. (2000). Ideals, perceptions, and evaluations in early relationship development. Journal of Personality and Social Psychology, 79, 933-940.

Frye, N. E., \& Karney, B. R. (2002). Being better or getting better? Social and temporal comparisons as coping mechanisms in close relationships. Personality and Social Psychology Bulletin, 28, 1287-1299.

Frye, N. E., \& Karney, B. R. (in press). Revision in memories of relationship development: Do biases persist over time? Personal Relationships.

Gottman, J. M. (1994). What predicts divorce? The relationship between marital processes and marital outcomes. Hillsdale, NJ: Erlbaum.

Gottman, J. M., Coan, J., Carrere, S., \& Swanson, C. (1998). Predicting marital happiness and stability from newlywed interactions. Journal of Marriage and the Family, 60, 5-22.

Hampson, S. E., Goldberg, L. R., \& John, O. P. (1987). Category-breadth and social-desirability values for 573 personality terms. European Journal of Personality, 1, 241-258.

Hampson, S. E., John, O. P., \& Goldberg, L. R. (1986). Category breadth and hierarchical structure in personality: Studies of asymmetries in judgments of trait implications. Journal of Personality and Social Psychology, 51, 37-54.

Hastorf, A. H., \& Cantril, H. (1954). They saw a game; a case study. Journal of Applied Social Psychology, 49, 129-134.

Helgeson, V. S. (1994). The effects of self-beliefs and relationship beliefs on adjustment to a relationship stressor. Personal Relationships, 1, 241-258.

Huprich, S. K. (2003). Depressive personality and its relationship to depressed mood, interpersonal loss, negative parental perceptions, and perfectionism. Journal of Nervous and Mental Disease, 191, 73-79.

Huston, T. L., Caughlin, J. P., Houts, R. M., Smith, S. E., \& George, L. J. (2001). The connubial crucible: Newlywed years as predictors of marital delight, distress, and divorce. Journal of Personality and Social Psychology, 80, 237-252.
Isaacowitz, D. M., \& Seligman, M. E. P. (2001). Is pessimism a risk factor for depressive mood among community-dwelling older adults? Behaviour Research and Therapy, 39, 255-272.

Jones, M. E., \& Stanton, A. L. (1988). Dysfunctional beliefs, belief similarity, and marital distress: A comparison of models. Journal of Social and Clinical Psychology, 7, 1-14.

Jussim, L. (1986). Self-fulfilling prophecies: A theoretical and integrative review. Psychological Review, 93, 429-445.

Jussim, L., \& Eccles, J. (1995). Naturally occurring interpersonal expectancies. In N. Eisenberg (Ed.), Social development: Review of personality and social psychology (Vol. 15, pp. 74-108). Thousand Oaks, CA: Sage.

Karney, B. R., \& Bradbury, T. N. (1995). The longitudinal course of marital quality and stability: A review of theory, method, and research. Psychological Bulletin, 118, 3-34.

Karney, B. R., \& Bradbury, T. N. (1997). Neuroticism, marital interaction, and the trajectory of marital satisfaction. Journal of Personality and Social Psychology, 72, 1075-1092.

Karney, B. R., \& Bradbury, T. N. (2000). Attributions in marriage: State or trait? A growth curve analysis. Journal of Personality and Social Psychology, 78, 295-309.

Karney, B. R., McNulty, J. K., \& Bradbury, T. N. (2001). Cognition and the development of close relationships. In G. J. O. Fletcher \& M. S. Clark (Eds.), Blackwell handbook in social psychology. Vol. 2: Interpersonal processes (pp. 32-59). Oxford, England: Blackwell Publishers Limited.

Karney, B. R., McNulty, J. K., \& Frye, N. (2001). A social-cognitive perspective on the maintenance and deterioration of relationship satisfaction. In J. H. Harvey \& A. E. Wenzel (Eds.), Close romantic relationships: Maintenance and enhancement (pp. 195-214). Mahwah, NJ: Erlbaum.

Kelley, H. H. (1950). The warm-cold variable in first impressions of persons. Journal of Personality, 18, 431-439.

Knee, C. R. (1998). Implicit theories of relationships: Assessment and prediction of romantic relationship initiation, coping and longevity. Journal of Personality and Social Psychology, 74, 360-370.

Locke, H. J., \& Wallace, K. M. (1959). Short marital adjustment prediction tests: Their reliability and validity. Marriage and Family Living, 21, 251-255.

McNulty, J. K., \& Karney, B. R. (2001). Attributions in marriage: Integrating specific and global evaluations of a relationship. Personality and Social Psychology Bulletin, 27, 943-955.

McNulty, J. K., \& Karney, B. R. (2002). Expectancy confirmation in appraisals of marital interactions. Personality and Social Psychology Bulletin, 28, 764-775.

Medvec, V. H., Madey, S. F., \& Gilovich, T. (1995). When less is more: Counterfactual thinking and satisfaction among Olympic medalists. Journal of Personality and Social Psychology, 69, 603-610.

Mellers, B. A., Schwartz, A., Ho, K., \& Ritov, I. (1997). Decision affect theory: Emotional reactions to the outcomes of risky options. Psychological Science, 8, 423-429.

Merton, R. K. (1948). The self-fulfilling prophecy. Antioch Review, 8 , 193-210.

Miller, D. T., \& Turnbull, W. (1986). Expectancies and interpersonal processes. Annual Review of Psychology, 37, 233-256.

Murray, S. L., \& Holmes, J. G. (1997). A leap of faith? Positive illusions in romantic relationships. Personality and Social Psychology Bulletin, $23,586-604$.

Murray, S. L., Holmes, J. G., \& Griffin, D. W. (1996a). The benefits of positive illusions: Idealization and the construction of satisfaction in close relationships. Journal of Personality and Social Psychology, 70, 79-98.

Murray, S. L., Holmes, J. G., \& Griffin, D. W. (1996b). The self-fulfilling nature of positive illusions in romantic relationships: Love is not blind, 
but prescient. Journal of Personality and Social Psychology, 71, 11551180.

Neff, L. A., \& Karney, B. R. (2002a). Judgments of a relationship partner: Specific accuracy but global enhancement. Journal of Personality, 70, 1077-1110.

Neff, L. A., \& Karney, B. R. (2002b). Self-evaluation motives in close relationships: A model of global enhancement and specific verification. In P. Noller \& J. A. Feeney (Eds.), Understanding marriage: Developments in the study of couple interaction (pp. 32-58). Cambridge, England: Cambridge University Press.

Neff, L. A., \& Karney, B. R. (2003). The dynamic structure of relationship perceptions: Differential importance as a strategy of relationship maintenance. Personality and Social Psychology Bulletin, 29, 1433-1446.

Neff, L. A., \& Karney, B. R. (2004). How does context affect intimate relationships? Linking external stress and cognitive processes within marriage. Personality and Social Psychology Bulletin, 30, 134-148.

Norton, R. (1983). Measuring marital quality: A critical look at the dependent variable. Journal of Marriage and the Family, 45, 141-151.

Olson, J. M., Roese, N. J., \& Zanna, M. P. (1998). Expectancies. In E. T. Higgins \& A. W. Kruglanski (Eds.), Social psychology: Handbook of basic principles (pp. 211-238). New York: Guilford Press.

O'Mahen, H. A., Beach, S. R. H., \& Banawan, S. F. (2001). Depression in marriage. In J. H. Harvey \& A. H. Wenzel (Eds.), Close romantic relationships: Maintenance and enhancement (pp. 299-319). Mahwah, NJ: Erlbaum.

Osgood, C. E., Suci, G. J., \& Tannenbaum, P. H. (1957). The measurement of meaning. Urbana: University of Illinois Press.

Peale, N. V. (1952). The power of positive thinking. New York: PrenticeHall.

Radcliffe, N. M., \& Klein, W. M. (2002). Dispositional, unrealistic, and comparative optimism: Differential relations with the knowledge and processing of risk information and beliefs about personal risk. Personality and Social Psychology Bulletin, 28, 836-846.

Raudenbush, S. W., Brennan, R. T., \& Barnett, R. C. (1995). A multivariate hierarchical model for studying psychological change within married couples. Journal of Family Psychology, 9, 161-174.

Roberts, R. E., Roberts, C. R., \& Chen, I. G. (2000). Fatalism and risk of adolescent depression. Psychiatry: Interpersonal and Biological Processes, 63, 239-252.

Robins, R. W., \& Beer, J. S. (2001). Positive illusions about the self: Short-term benefits and long-term costs. Journal of Personality and Social Psychology, 80, 340-352.
Rosenthal, R., \& Jacobson, L. (1968). Pygmalion in the classroom: Teacher expectation and pupils' intellectual development. New York: Holt, Rinehart \& Winston.

Shepperd, J. A., \& McNulty, J. K. (2002). The affective consequences of expected and unexpected outcomes. Psychological Science, 13, 85-88.

Sherif, M. (1960). Some needed concepts in the study of social attitudes. In J. G. Peatman \& E. L. Hartley (Eds.), Festschrift for Gardner Murphy (pp. 194-213). Oxford, England: Harper.

Sillars, A. L., Coletti, S. F., Parry, D., \& Rogers, M. A. (1982). Coding verbal conflict tactics: Nonverbal and perceptual correlates of the "avoidance-distributive-integrative" distinction. Human Communication Research, 9, 83-95.

Snyder, M. (1984). When belief creates reality. In L. Berkowitz (Ed.), Advances in experimental social psychology (Vol. 18, pp. 248-305). Orlando, FL: Academic Press.

Snyder, M., Tanke, E. D., \& Berscheid, E. (1977). Social perception and interpersonal behavior: On the self-fulfilling nature of social stereotypes. Journal of Personality and Social Psychology, 35, 656-666.

South, S. J., \& Spitze, G. (1986). Determinants of divorce over the marital life course. American Sociological Review, 51, 583-590.

Stanley, S. M., Blumberg, S. L., \& Markman, H. J. (Eds.). (1999). Helping couples fight for their marriages: The PREP approach. Philadelphia: Brunner/Mazel.

Swann, W. B. (1984). Quest for accuracy in person perception: A matter of pragmatics. Psychological Review, 91, 457-477.

Swann, W. B. (1990). To be adored or to be known? The interplay of self-enhancement and self-verification. In E. T. Higgins \& R. M Sorrentino (Eds.), Handbook of motivation and cognition: Foundations of social behavior (Vol. 2, pp. 408-448). New York: Guilford Press.

Swann, W. B., de la Ronde, C., \& Hixon, J. G. (1994) Authenticity and positivity strivings in marriage and courtship. Journal of Personality and Social Psychology, 66, 857-869.

Taylor, S. E., \& Brown, J. D. (1994). Positive illusions and well-being revisited: Separating fact from fiction. Psychological Bulletin, 116, 21-27.

Thibaut, J. W., \& Kelley, H. H. (1959). The social psychology of groups. Oxford, England: Wiley.

Vogel, D. L., \& Karney, B. R. (2002). Demands and withdrawal in relationships: Elaborating on the social structure hypothesis. Journal of Social and Personal Relationships, 19, 685-701.

Wiebe, D. J., \& Black, D. (1997). Illusional beliefs in the context of risky sexual behaviors. Journal of Applied Social Psychology, 27, 1727-1749. 
Appendix

A Measure of Expectations for Partner

In response to the following statements, indicate how strongly you agree by filling in the appropriate bubble.

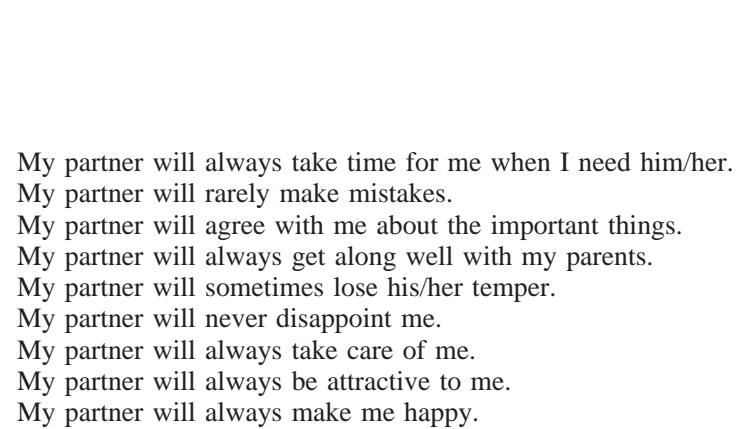

My partner will sometimes lose his/her temper.

My partner will never disappoint me.

My partner will always make me happy.

\begin{tabular}{lllllll}
1 & 2 & 3 & 4 & 5 & 6 & 7 \\
\hline 0 & $\bigcirc$ & $\bigcirc$ & $\bigcirc$ & $\bigcirc$ & $\bigcirc$ & $\bigcirc$ \\
$\bigcirc$ & $\bigcirc$ & $\bigcirc$ & $\bigcirc$ & $\bigcirc$ & $\bigcirc$ & $\bigcirc$ \\
$\bigcirc$ & $\bigcirc$ & $\bigcirc$ & $\bigcirc$ & $\bigcirc$ & $\bigcirc$ & $\bigcirc$ \\
$\bigcirc$ & $\bigcirc$ & $\bigcirc$ & $\bigcirc$ & $\bigcirc$ & $\bigcirc$ & $\bigcirc$ \\
$\bigcirc$ & $\bigcirc$ & $\bigcirc$ & $\bigcirc$ & $\bigcirc$ & $\bigcirc$ & $\bigcirc$ \\
$\bigcirc$ & $\bigcirc$ & $\bigcirc$ & $\bigcirc$ & $\bigcirc$ & $\bigcirc$ & $\bigcirc$ \\
$\bigcirc$ & $\bigcirc$ & $\bigcirc$ & $\bigcirc$ & $\bigcirc$ & $\bigcirc$ & $\bigcirc$ \\
$\bigcirc$ & $\bigcirc$ & $\bigcirc$ & $\bigcirc$ & $\bigcirc$ & $\bigcirc$ & $\bigcirc$ \\
$\bigcirc$ & $\bigcirc$ & $\bigcirc$ & $\bigcirc$ & $\bigcirc$ & $\bigcirc$ & $\bigcirc$
\end{tabular}

Received May 13, 2003

Revision received October 31, 2003

Accepted November 5, 2003

\section{E-Mail Notification of Your Latest Issue Online!}

Would you like to know when the next issue of your favorite APA journal will be available online? This service is now available to you. Sign up at http://watson.apa.org/ notify/and you will be notified by e-mail when issues of interest to you become available! 